\title{
Using IBM SPSS statistics to identify predictors of electricity consumption in a UK supermarket
}

\author{
M. Braun ${ }^{1}$, H. Altan ${ }^{2} \&$ S. Beck ${ }^{1}$ \\ ${ }^{I}$ Department of Mechanical Engineering, University of Sheffield, UK \\ ${ }^{2}$ School of Architecture, University of Sheffield, UK
}

\begin{abstract}
In order to save energy in supermarkets, technical solutions need to be supported by appropriate maintenance and operation tools. These tools should provide sufficient information to detect unusual levels of energy consumption. Therefore this paper presents an explorative study on a well sub-metered grocery supermarket in the UK Yorkshire and Humber region. The data collected for this study included electricity consumption, footfall data, inside and outside climate data, as well as settings of all relevant building timers. Thereafter the meaningfulness of these predictors was evaluated with the 'stepwise' option in the linear regression section of SPSS. The results generally show a very good fit between the mathematical regression model and the measured data $(r>0.95)$. The only exception was the refrigeration model for all five days. Upon further investigation it was found that the current reading for one of these five days was unusually low (proving the effectiveness of the method to detect abnormalities). Based on these results it can be argued that it should be possible to use data routinely gathered by supermarkets or otherwise easily obtained to detect greater abnormalities and thus keep energy consumption to a minimum.

Keywords: supermarket, electricity consumption, regression analysis, SPSS.
\end{abstract}

\section{Introduction}

In the UK, supermarkets take energy savings quite seriously, so much so that people wonder whether there are limits to energy efficiency for supermarkets (Sullivan and Gouldson [1]). A lot of attention has been given to what technology can do to reduce energy use in supermarkets. For instance, Rhiemeier 
et al. [2] present in their report a comprehensive overview of fluorinated hydrocarbons free refrigeration systems available in Europe. They also explore the energy efficiency of these systems and contrast them to more conventional systems.

Sole reliance on more energy efficient technologies is what Mohammed et al. [3] refer to as "technological fixes". They found in their literature survey that this approach is very effective in conserving energy in the short term. However, this line of attack does allow users to keep their old, bad habits and waste energy the same old way. One example was presented by Hansen and Rasul [4] who examined a poorly performing air conditioning system in a supermarket. They found that the premature aging of the system was due to the coastal climate and poor maintenance. Although they recommended an upgrade in systems capability, they also emphasized the importance of preventative maintenance, something that, it seems, had been neglected before.

In his article on energy efficiency through improved maintenance, Jeremić [5] poses the question of who or what can motivate employees to make an optimal contribution to improving a company's energy efficiency. Possible links between the energy performance and the educational and pay level of operation and maintenance staff has been suggested by Yik et al. [6]. In addition to this, this paper points out that the "key barriers to energy efficiency improvement in existing buildings are the knowledge, motivation and financial barriers". One of the knowledge barriers is the "lack of awareness of how energy inefficient a building has become". Because being aware of a problem is the first step to solving it, the stimulus alerting people to a problem should be sufficiently high to attract their attention [3].

The discussion so far leads to the objective of this paper, which is to use the case study of a supermarket in North East England to explore to which degree parameters, such as temperature, building timers or footfall, can be used to track electricity consumption. Furthermore, it investigates if excluding internal temperature and humidity data, will still lead to usable predictive models.

This investigation is deemed necessary because it could be argued that the alerts in the supermarket investigated here are insufficient. This supermarket has a large number of alerts which communicate a hard failure (e.g. refrigeration plant shut down) and a comparison of daily consumption with the previous year. However, this regime does not take into consideration any outside temperature variation and is not detailed enough to differentiate between the three operational stages of the supermarket (i.e. closed, product stocking and open). This could lead to a lower level of maintenance than required because the operational drift is allowed to alter the alert level. Therefore a different approach should be investigated based on more objective parameters.

In order to compare the actual consumption with the expected levels, two fundamentally different approaches can be used (ASHRAE [7]): forward models and inverse models. The forward modelling approach, which models components and their interaction, has attracted a lot of attention (see for instance Arias [8]). However, in this paper a more time efficient inverse model has been developed to model expected consumption. 
The study uses the statistical software package IBM SPSS Statistics to perform a linear regression analysis and finds that abnormal behaviour can indeed be detected and that four-predictor models perform very well.

\section{Method}

The supermarket studied here is located close to the cost in North East England and has a total size of $1725 \mathrm{~m}^{2}$ (sales area $\approx 1250 \mathrm{~m}^{2}$ ). As this area sells mainly easily perishable food, there is a large section with open refrigerated shelves served by two refrigeration plants. Three stand alone freezer cabinets hold frozen goods. In addition, the supermarket also has a small café/restaurant and a bakery with two $7.5 \mathrm{~kW}$ ovens.

The operation of this supermarket was observed on $6^{\text {th }}$ Nov 2012 and data for this day as well as for four context days (30 Oct, 5, 7 and 13 Nov 2012) was obtained. In particular the following data was collected and analysed:

- Total supermarket electricity consumption (hereafter referred to as "total consumption"): Data from six sub-meters, which cover all the areas of the supermarket, was downloaded in 15-sec intervals. After that the data was averaged for 15-min intervals and added together to give the total consumption.

- Total electricity consumption of the two refrigeration plants (hereafter referred to as "refrigeration consumption"): Data from two sub-meters for the two refrigeration plants was downloaded in 15-sec intervals. After that the data was averaged for 15-min intervals and added together to give the total consumption for the refrigeration effort.

- Footfall: Data was obtained in 15-min intervals.

- Inside temperature $\left(\vartheta_{\text {in }}\right)$ and relative humidity $\left(\mathrm{RH}_{\mathrm{in}}\right)$ : The data of a combined sensor inside the sales area was downloaded in 15 -sec intervals and then averaged for 15-min intervals.

- Outside temperature $\left(\vartheta_{\text {out }}\right)$ and relative humidity $\left(\mathrm{RH}_{\text {out }}\right)$ : The data of a combined sensor on the north facing supermarket wall was downloaded in 15 -sec intervals and then averaged for 15-min intervals.

- Settings of building timers and night cover timings as detailed in Table 1.

Table 1: $\quad$ Building timers and night cover timings.

\begin{tabular}{|l|l|c|c|c|c|}
\hline \multicolumn{1}{|c|}{ Abbr. } & \multicolumn{1}{|c|}{ Description } & On & Off & On & Off \\
\hline Light & Store light during trading hours (timer) & $07: 55$ & $20: 00$ & & \\
\hline HVAC & HVAC enabled (timer) & $08: 00$ & $16: 00$ & $18: 00$ & $19: 30$ \\
\hline Cover & Night cover for refrigerated display cabinets & & $6: 30$ & $20: 00$ & \\
\hline
\end{tabular}

Firstly the collected data was used to see if the data for the day of the site visit was representative. After this was established, Excel was used to prepare a standardised data set including the total consumption, refrigeration consumption and all predictors. The third step was to use SPSS to perform a number of multiple regression analyses. 


\subsection{Multiple regression analysis}

Regression analysis uses a mathematical model to state the relationship between a dependent variable and one or more predictor variable(s) (Montgomery et al. [9]). The equation for multiple linear regression can be written as:

where:

$$
y=b_{0}+b_{1} x_{1}+\cdots+b_{n} x_{n}+e
$$

$y$ : Dependent variable

$x_{1} \ldots x_{n}:$ Predictors

$b_{0} \ldots b_{n}$ : Estimates of regression coefficient

$e$ : Error term

Data collected through observation (e.g. measurements) is used to compute the parameters $b_{0} \ldots b_{n}$, normally using the least square algorithm. However, before actually attempting to work out the estimated regression parameters, it is good practice to test for multicollinearity between all predictors. If there is a strong correlation (i.e. the absolute value exceeds 0.7 ) between a pair of predictors, then including both of them may create problems such as separating the effects of individual parameters (Anderson et al. [10]).

If the following assumptions are met, then the statistical significance of the whole equation as well as estimated regression parameters can be assessed using either the F-test (whole equation), t-test (individual regression parameter) or their corresponding $p$-values $[9,10]$ :

1. The error term has an average of zero.

2. The errors are normally distributed.

3. The error term has a constant variance.

4. The relationship between the dependent variable and the predictor(s) is at least approximately linear.

5. The errors are not correlated to the predictors.

The validity of these assumptions can be tested by using the error term $e$ in equation (1) in a residual analysis.

If a predictor is not statistically significant, it can be excluded. In addition to this, if a predictor does not change the goodness of fit (related to correlation coefficient r) significantly, it may also be ignored. In this study predictors, which do not improve $r^{2}$ by $0.5 \%$ or more, were not included.

\subsection{Multiple regression analysis with SPSS}

IBM SPSS Statistics is a predictive analytics software which incorporates many statistical tools including regression analysis. The option chosen for this analysis was linear (see right-hand side in Figure 1). Selecting this option opens up the window displayed on the right hand side in Figure 1. This window allows the following methods:

- Enter: Forces the chosen predictor(s) to enter the model.

- Stepwise: Enters or removes one predictor at a time until the best model (based on the data presented) is found.

- Remove: Removes the chosen predictor(s) from the previous model. 
- $\quad$ Backward: Starts with all predictors and removes the weakest until only significant predictors are left.

- Forward: Starts with the strongest predictors and includes one at a time until all statistically significant predictors have been included.
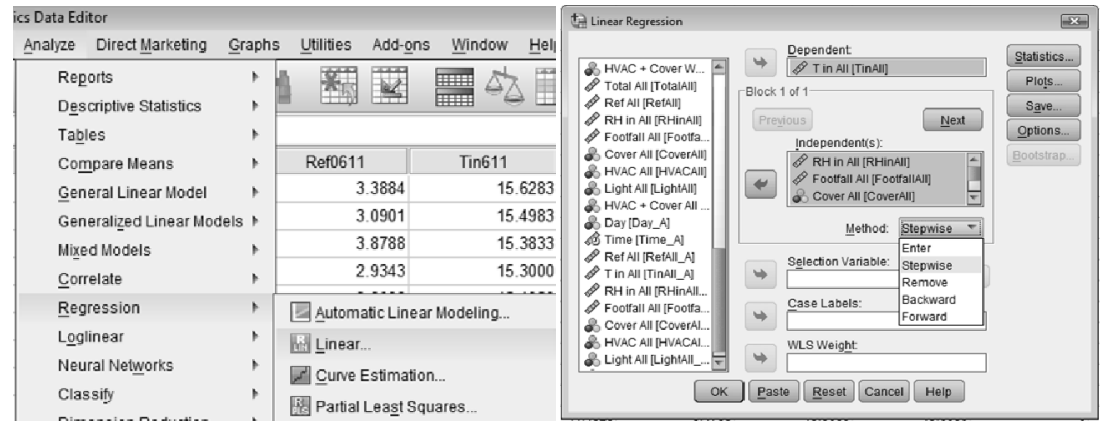

Figure 1: $\quad$ SPSS regression analysis menus.

The method chosen here was 'stepwise' which starts with the strongest predictor and then includes the second if its p-value is not greater than 0.05 and so on. If a previously included predictor should be assigned a p-value of 0.1 or greater, then it will be excluded ( 0.05 and 0.1 are default settings). In addition to this, relevant plots were selected to verify the underlying assumptions. Amongst other parameters the value for ' $r^{2}$ change' was selected to indicate when a new model improved the coefficient of determination by less $0.5 \%$. This model was also used to produce the graphs in the 'Result' section below.

\section{Results}

Table 2 shows the results of the bivariate correlation analysis in SPSS and indicates that $\vartheta_{\text {in }}$ is closely related to $\mathrm{RH}_{\text {in }}$, Footfall and Light. The predictor Light, in turn, is also strongly correlated with Footfall, Cover and HVAC.

Table 2: $\quad$ Collinearity table for predictors (5 days).

\begin{tabular}{|l|c|c|c|c|c|c|c|}
\hline & $\vartheta_{\text {out }}$ & $\mathrm{RH}_{\text {out }}$ & $\vartheta_{\text {in }}$ & $\mathrm{RH}_{\text {in }}$ & Footfall & Cover & HVAC \\
\hline $\mathrm{RH}_{\text {out }}$ & -0.412 & & & & & & \\
\hline$\vartheta_{\text {in }}$ & 0.653 & -0.665 & & & & & \\
\hline $\mathrm{RH}_{\text {in }}$ & -0.387 & 0.576 & $\mathbf{- 0 . 8 2}$ & & & & \\
\hline Footfall & 0.480 & -0.566 & $\mathbf{0 . 8 3 5}$ & -0.689 & & & \\
\hline Cover & 0.367 & -0.395 & 0.66 & -0.497 & 0.692 & & \\
\hline HVAC & -0.357 & 0.385 & -0.648 & 0.467 & -0.673 & -0.699 & \\
\hline Light & 0.45 & -0.49 & $\mathbf{0 . 7 8 6}$ & -0.605 & $\mathbf{0 . 7 9 7}$ & $\mathbf{0 . 8 6 3}$ & $\mathbf{- 0 . 8 0 9}$ \\
\hline
\end{tabular}

The tables below show the estimates of the regression parameters $b_{i}$ and their $\mathrm{t}$-value(s). They also display the correlation coefficient $r$ (denoting the goodness of fit), the coefficient of determination $\mathrm{r}^{2}$ (indicating how much variation can be explained), $r^{2}$ change and the value for the F-statistics for each model. 
Table 3: Analysis results - total consumption, indoor climate (all five days).

\begin{tabular}{|c|c|c|c|c|c|c|c|}
\hline \multicolumn{2}{|r|}{ Model } & $\mathrm{b}$ & $\mathrm{t}$ & $\mathrm{r}$ & $r^{2}$ & $r^{2}$ change & $\mathrm{F}$ \\
\hline \multirow{2}{*}{1} & \begin{tabular}{|l|} 
(Constant) \\
\end{tabular} & 0.000 & -0.024 & \multirow{2}{*}{0.921} & \multirow{2}{*}{0.849} & \multirow{2}{*}{0.849} & \multirow{2}{*}{2677.5} \\
\hline & Light & 0.920 & 51.74 & & & & \\
\hline \multirow{3}{*}{2} & (Constant) & -0.070 & -4.74 & \multirow{3}{*}{0.951} & \multirow{3}{*}{0.905} & \multirow{3}{*}{0.056} & \multirow{3}{*}{2265.4} \\
\hline & Light & 0.515 & 18.40 & & & & \\
\hline & Cover & 0.474 & 16.78 & & & & \\
\hline \multirow{4}{*}{3} & \begin{tabular}{|l|} 
(Constant) \\
\end{tabular} & -0.068 & -5.98 & \multirow{4}{*}{0.972} & \multirow{4}{*}{0.945} & \multirow{4}{*}{0.041} & \multirow{4}{*}{2740.3} \\
\hline & Light & 0.238 & 9.19 & & & & \\
\hline & \begin{tabular}{|l|} 
Cover \\
\end{tabular} & 0.474 & 22.12 & & & & \\
\hline & HVAC & -0.343 & -18.77 & & & & \\
\hline \multirow{5}{*}{4} & (Constant) & -0.068 & -6.51 & \multirow{5}{*}{0.976} & \multirow{5}{*}{0.952} & \multirow{5}{*}{0.007} & \multirow{5}{*}{2343.9} \\
\hline & \begin{tabular}{|l|} 
Light \\
\end{tabular} & 0.131 & 4.71 & & & & \\
\hline & Cover & 0.484 & 23.97 & & & & \\
\hline & HVAC & -0.0338 & -19.69 & & & & \\
\hline & $\vartheta_{\text {in }}$ & 0.131 & 8.01 & & & & \\
\hline \multirow{6}{*}{5} & (Constant) & -0.060 & -5.65 & \multirow{6}{*}{0.976} & \multirow{6}{*}{0.953} & \multirow{6}{*}{0.001} & \multirow{6}{*}{1928.5} \\
\hline & \begin{tabular}{|l|} 
Light \\
\end{tabular} & 0.110 & 3.96 & & & & \\
\hline & \begin{tabular}{|l|} 
Cover \\
\end{tabular} & 0.480 & 24.06 & & & & \\
\hline & HVAC & -0.334 & -19.64 & & & & \\
\hline & $\vartheta_{\text {in }}$ & 0.090 & 4.64 & & & & \\
\hline & Footfall & 0.067 & 3.72 & & & & \\
\hline & (Constant) & -0.059 & -5.63 & \multirow{7}{*}{0.977} & & & \\
\hline & \begin{tabular}{|l|} 
Light \\
\end{tabular} & 0.112 & 4.03 & & & & \\
\hline & \begin{tabular}{|l|} 
Cover \\
\end{tabular} & 0.481 & 24.17 & & & & \\
\hline 6 & HVAC & -0.335 & -19.77 & & 0.954 & 0.000 & 1619.5 \\
\hline & $\vartheta_{\text {in }}$ & 0.066 & 2.91 & & & & \\
\hline & Footfall & 0.071 & 3.94 & & & & \\
\hline & $\vartheta_{\text {out }}$ & 0.028 & 2.11 & & & & \\
\hline
\end{tabular}

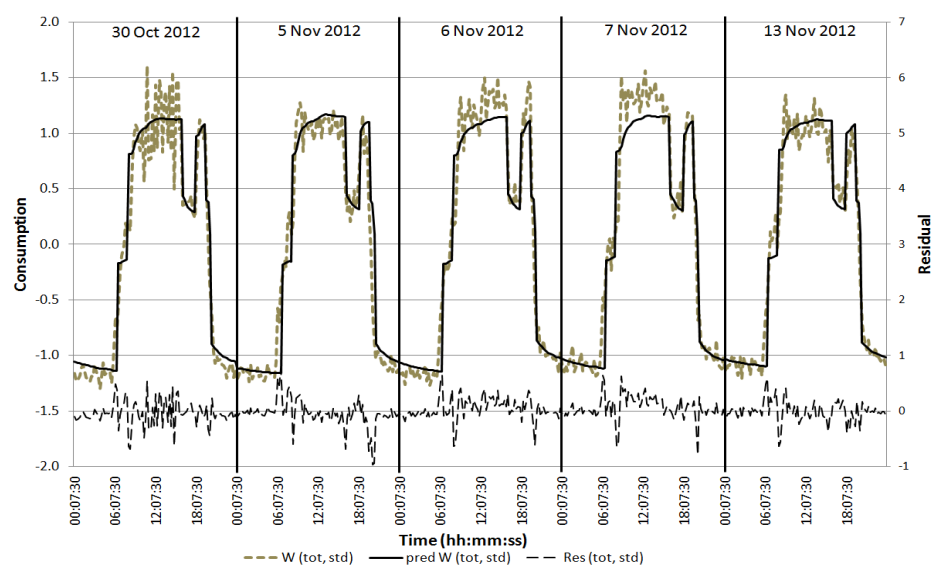

Figure 2: $\quad$ Total consumption - predictors: light, cover, HVAC and $\vartheta_{\text {in. }}$ 
Table 3 indicates that after the fourth step there was only an insignificant improvement of the model. Therefore model 4 was used to plot Figure 2. Both Table 3 and Figure 2 suggest that there is a very good fit $(r=0.976)$ of the selected model to the measure data.

Table 4: Analysis results - refrigeration consumption, all predictors (all five days).

\begin{tabular}{|c|c|c|c|c|c|c|c|}
\hline \multicolumn{2}{|r|}{ Model } & $\mathrm{b}$ & $\mathrm{t}$ & $\mathrm{r}$ & $\mathrm{r}^{2}$ & $r^{2}$ change & $\mathrm{F}$ \\
\hline \multirow{2}{*}{1} & (Constant) & -0.002 & -0.101 & \multirow{2}{*}{0.846} & \multirow[b]{2}{*}{0.716} & \multirow{2}{*}{0.717} & \multirow{2}{*}{1208.4} \\
\hline & Light & 0.844 & 34.762 & & & & \\
\hline \multirow{3}{*}{2} & (Constant) & -0.069 & -2.990 & \multirow{3}{*}{0.876} & \multirow{3}{*}{0.768} & \multirow{3}{*}{0.051} & \multirow{3}{*}{789.4} \\
\hline & Light & 0.457 & 10.487 & & & & \\
\hline & Cover & 0.453 & 10.281 & & & & \\
\hline \multirow{4}{*}{3} & (Constant) & -0.072 & -3.458 & \multirow{4}{*}{0.900} & \multirow{4}{*}{0.822} & \multirow{4}{*}{0.043} & \multirow{4}{*}{679.7} \\
\hline & Light & 0.337 & 8.195 & & & & \\
\hline & Cover & 0.472 & 11.842 & & & & \\
\hline & $\vartheta_{\text {out }}$ & 0.232 & 10.371 & & & & \\
\hline \multirow{5}{*}{4} & (Constant) & -0.052 & -2.546 & \multirow{5}{*}{0.907} & \multirow{5}{*}{0.830} & \multirow{5}{*}{0.011} & \multirow{5}{*}{547.7} \\
\hline & Light & 0.211 & 4.560 & & & & \\
\hline & Cover & 0.468 & 12.070 & & & & \\
\hline & $\vartheta_{\text {out }}$ & 0.204 & 9.173 & & & & \\
\hline & Footfall & 0.162 & 5.433 & & & & \\
\hline \multirow{6}{*}{5} & (Constant) & -0.045 & -2.264 & & & & \\
\hline & Light & 0.229 & 5.052 & & & & \\
\hline & Cover & 0.456 & 12.013 & 0.11 & 0828 & 0008 & 16312 \\
\hline & $\vartheta_{\text {out }}$ & 0.224 & 10.107 & 0.911 & 0.838 & 0.008 & 463.13 \\
\hline & Footfall & 0.205 & 6.733 & & & & \\
\hline & $\mathrm{RH}_{\text {out }}$ & 0.113 & 4.806 & & & & \\
\hline & (Constant) & -0.054 & -2.755 & & & & \\
\hline & Light & 0.173 & 3.724 & & & & \\
\hline & Cover & 0.462 & 12.396 & & & & \\
\hline 6 & $\vartheta_{\text {out }}$ & 0.171 & 6.861 & 0.915 & 0.837 & 0.006 & 403.4 \\
\hline & Footfall & 0.136 & 4.020 & & & & \\
\hline & $\mathrm{RH}_{\text {out }}$ & 0.154 & 6.185 & & & & \\
\hline & $\vartheta_{\text {in }}$ & 0.198 & 4.316 & & & & \\
\hline & (Constant) & -0.053 & -2.843 & & & & \\
\hline & Light & 0.142 & 3.254 & & & & \\
\hline & Cover & 0.451 & 12.898 & & & & \\
\hline 7 & $\vartheta_{\text {out }}$ & 0.097 & 3.880 & 0926 & 0857 & 0021 & 4044 \\
\hline 1 & Footfall & 0.142 & 4.482 & 0.926 & & & \\
\hline & $\mathrm{RH}_{\text {out }}$ & 0.145 & 6.191 & & & & \\
\hline & $\vartheta_{\text {in }}$ & 0.488 & 8.794 & & & & \\
\hline & $\mathrm{RH}_{\text {in }}$ & 0.271 & 8.245 & & & & \\
\hline & (Constant) & 0.271 & 8.245 & & & & \\
\hline & Light & -0.053 & -2.865 & & & & \\
\hline & Cover & 0.089 & 1.842 & & & & \\
\hline & $\vartheta_{\text {out }}$ & 0.451 & 12.985 & & & & \\
\hline 8 & Footfall & 0.102 & 4.070 & 0.927 & 0.859 & 0.002 & 358.1 \\
\hline & $\mathrm{RH}_{\text {out }}$ & 0.137 & 4.317 & & & & \\
\hline & $\vartheta_{\text {in }}$ & 0.142 & 6.098 & & & & \\
\hline & $\mathrm{RH}_{\text {in }}$ & 0.261 & 7.922 & & & & \\
\hline & HVAC & 0.475 & 8.554 & & & & \\
\hline
\end{tabular}




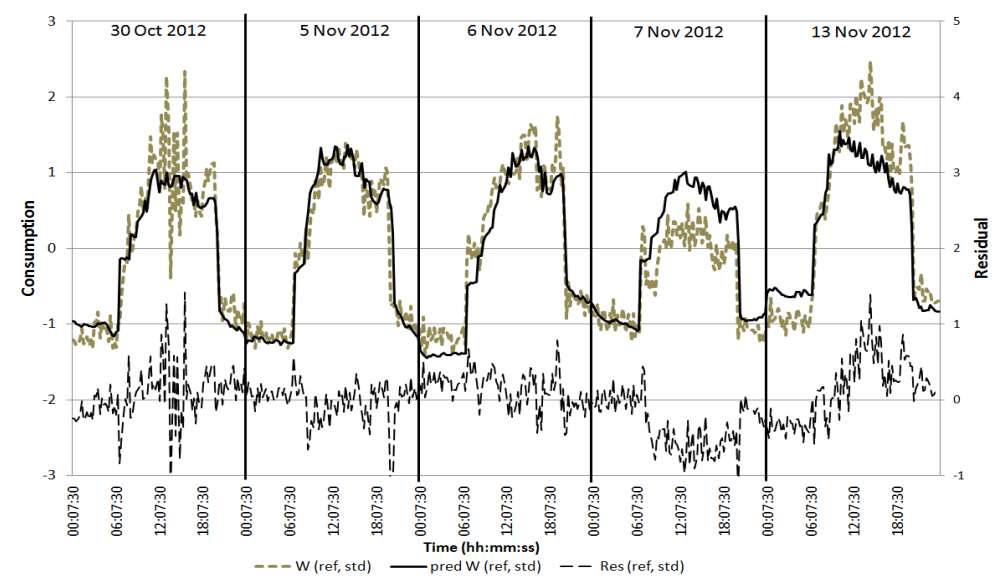

Figure 3: Refrigeration consumption - predictors: light, cover, $\vartheta_{\text {out }}$, Footfall, $\mathrm{RH}_{\text {out }}, \vartheta_{\text {in }}$ and $\mathrm{RH}_{\text {in. }}$

Table 5: $\quad$ Analysis result - refrigeration consumption, all predictors (day 1$3)$.

\begin{tabular}{|c|c|c|c|c|c|c|c|}
\hline \multicolumn{2}{|r|}{ Model } & $\mathrm{b}$ & $\mathrm{t}$ & $\mathrm{r}$ & $r^{2}$ & $r^{2}$ change & $\mathrm{F}$ \\
\hline \multirow{2}{*}{1} & (Constant) & 0.000 & 0.008 & \multirow[b]{2}{*}{0.901} & \multirow{2}{*}{0.812} & \multirow{2}{*}{0.813} & \multirow[b]{2}{*}{1240.2} \\
\hline & Light & 0.901 & 35.216 & & & & \\
\hline \multirow{3}{*}{2} & (Constant) & 0.000 & 0.010 & \multirow{3}{*}{0.928} & \multirow{3}{*}{0.859} & \multirow{3}{*}{0.048} & \multirow{3}{*}{877.6} \\
\hline & Light & 0.527 & 12.024 & & & & \\
\hline & Cover & 0.434 & 9.866 & & & & \\
\hline \multirow{4}{*}{3} & (Constant) & 0.000 & 0.026 & \multirow{4}{*}{0.955} & \multirow{4}{*}{0.912} & \multirow{4}{*}{0.052} & \multirow{4}{*}{987.0} \\
\hline & Light & 0.209 & 4.917 & & & & \\
\hline & Cover & 0.459 & 13.152 & & & & \\
\hline & $\vartheta_{\text {in }}$ & 0.375 & 13.010 & & & & \\
\hline \multirow{5}{*}{4} & (Constant) & 0.000 & 0.022 & \multirow{5}{*}{0.958} & \multirow{5}{*}{0.917} & \multirow{5}{*}{0.005} & \multirow{5}{*}{791.3} \\
\hline & Light & 0.166 & 3.904 & & & & \\
\hline & Cover & 0.452 & 13.343 & & & & \\
\hline & $\vartheta_{\text {in }}$ & 0.297 & 8.967 & & & & \\
\hline & Footfall & 0.141 & 4.337 & & & & \\
\hline \multirow{6}{*}{5} & (Constant) & 0.000 & 0.012 & \multirow{6}{*}{0.959} & \multirow{6}{*}{0.920} & \multirow{6}{*}{0.002} & \multirow{6}{*}{652.3} \\
\hline & Light & 0.169 & 4.035 & & & & \\
\hline & Cover & 0.459 & 13.687 & & & & \\
\hline & $\vartheta_{\text {in }}$ & 0.211 & 4.843 & & & & \\
\hline & Footfall & 0.149 & 4.624 & & & & \\
\hline & $\vartheta_{\text {out }}$ & 0.089 & 2.969 & & & & \\
\hline \multirow{7}{*}{6} & (Constant) & 0.000 & 0.012 & \multirow{7}{*}{0.961} & \multirow{7}{*}{0.924} & \multirow{7}{*}{0.003} & \multirow{7}{*}{566.0} \\
\hline & Light & 0.098 & 2.126 & & & & \\
\hline & Cover & 0.460 & 13.992 & & & & \\
\hline & $\vartheta_{\text {in }}$ & 0.205 & 4.770 & & & & \\
\hline & Footfall & 0.132 & 4.138 & & & & \\
\hline & $\vartheta_{\text {out }}$ & 0.103 & 3.475 & & & & \\
\hline & HVAC & 0.098 & 3.412 & & & & \\
\hline
\end{tabular}

Figure 3 is the plot of model 7 in Table 4 and shows a relatively poor fit for days 4 and 5. Upon closer investigation of the data it was found that the current readings for day 4 displayed unusual behaviour (low and relatively flat). As this 


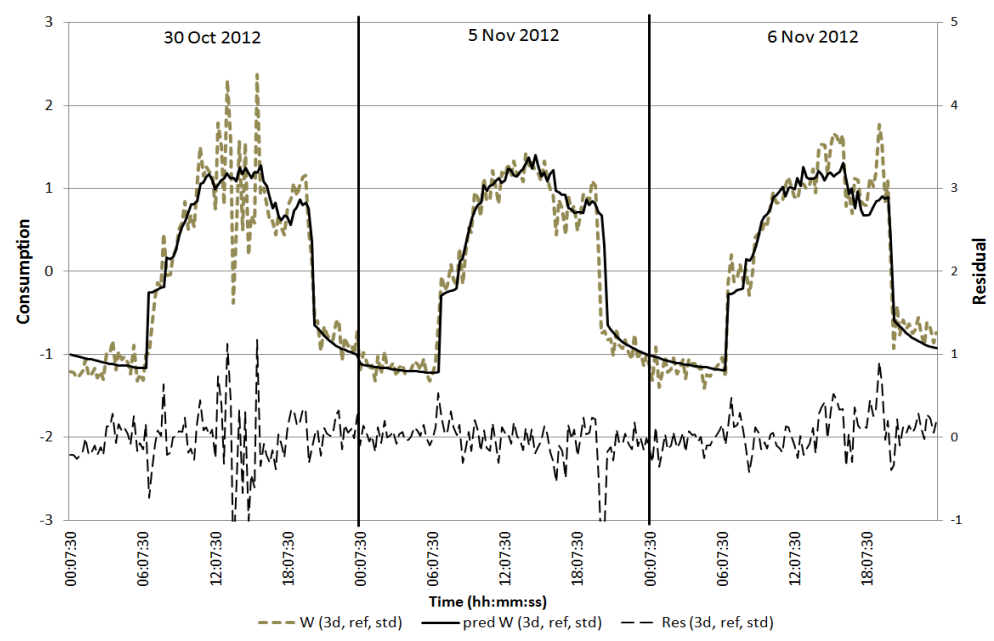

Figure 4: Refrigeration consumption (first 3 days) - predictors: light, cover, $\vartheta_{\text {in }}$ and footfall.

Table 6: Analysis result - total consumption, outside climate (all five days).

\begin{tabular}{|c|c|c|c|c|c|c|c|}
\hline \multicolumn{2}{|r|}{ Model } & $\mathrm{b}$ & $\mathrm{t}$ & $\mathrm{r}$ & $\mathrm{r}^{2}$ & $\mathrm{r}^{2}$ change & $\mathrm{F}$ \\
\hline \multirow{2}{*}{1} & (Constant) & 0.000 & -0.024 & \multirow{2}{*}{0.921} & \multirow{2}{*}{0.849} & \multirow{2}{*}{0.849} & \multirow{2}{*}{2677.5} \\
\hline & Light & 0.920 & 51.744 & & & & \\
\hline \multirow{3}{*}{2} & (Constant) & -0.070 & -4.736 & \multirow{3}{*}{0.951} & \multirow{3}{*}{0.904} & \multirow{3}{*}{0.056} & \multirow{3}{*}{2265.4} \\
\hline & Light & 0.515 & 18.399 & & & & \\
\hline & Cover & 0.474 & 16.781 & & & & \\
\hline \multirow{4}{*}{3} & (Constant) & -0.067 & -5.979 & \multirow{4}{*}{0.972} & \multirow{4}{*}{0.945} & \multirow{4}{*}{0.041} & \multirow{4}{*}{2740.3} \\
\hline & Light & 0.238 & 9.189 & & & & \\
\hline & Cover & 0.474 & 22.115 & & & & \\
\hline & HVAC & -0.343 & -18.772 & & & & \\
\hline \multirow{5}{*}{4} & (Constant) & -0.053 & -4.966 & \multirow{5}{*}{0.975} & \multirow{5}{*}{0.951} & \multirow{5}{*}{0.006} & \multirow{5}{*}{2305.8} \\
\hline & Light & 0.147 & 5.365 & & & & \\
\hline & Cover & 0.473 & 23.271 & & & & \\
\hline & HVAC & -0.333 & -19.183 & & & & \\
\hline & Footfall & 0.114 & 7.469 & & & & \\
\hline \multirow{6}{*}{5} & (Constant) & -0.056 & -5.268 & \multirow{6}{*}{0.976} & \multirow{6}{*}{0.923} & \multirow{6}{*}{0.002} & \multirow{6}{*}{1911.7} \\
\hline & Light & 0.133 & 4.895 & & & & \\
\hline & Cover & 0.477 & 23.848 & & & & \\
\hline & HVAC & -0.335 & -19.634 & & & & \\
\hline & Footfall & 0.100 & 6.449 & & & & \\
\hline & $\vartheta_{\text {out }}$ & 0.048 & 4.168 & & & & \\
\hline
\end{tabular}

casts doubt on the validity of the reading during the $5^{\text {th }}$ day also, both days were discarded. However, this indicates that, with this approach, behaviour which is out of the ordinary can be detected.

Table 5 shows the results of the regression analysis using only the first three days. Model 4 was chosen to be plotted (see Figure 4). This plot shows a better fit with the measured results which is also reflected in a stronger correlation $(\mathrm{r}=0.958)$. 


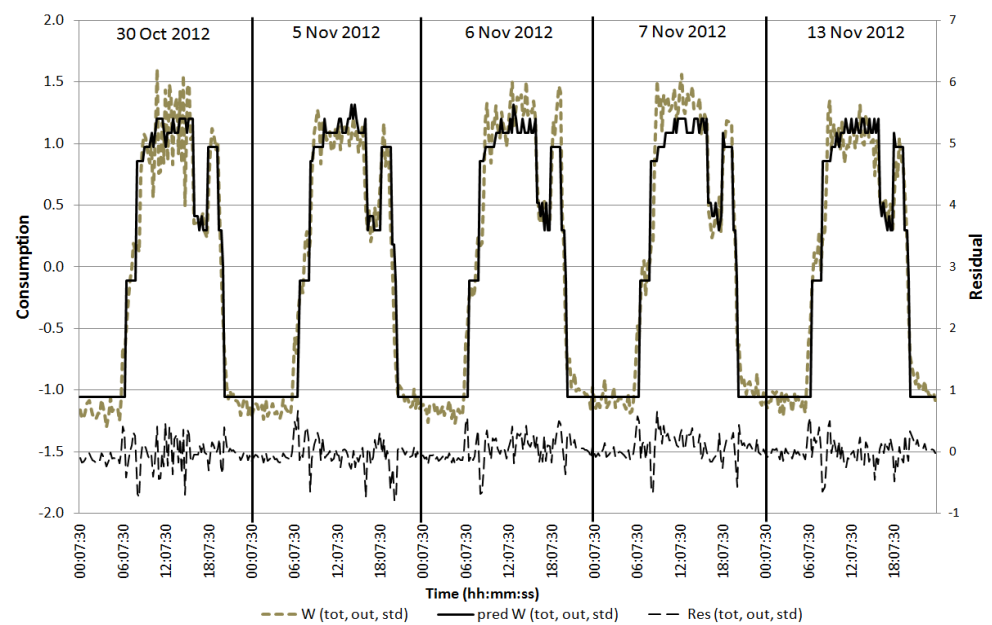

Figure 5: Total consumption - predictors: light, cover, HVAC and footfall.

Table 7: Analysis result - refrigeration consumption, outside climate (days $1-3)$.

\begin{tabular}{|c|c|c|c|c|c|c|c|}
\hline \multicolumn{2}{|r|}{ Model } & $\mathrm{b}$ & $\mathrm{t}$ & $\mathrm{r}$ & $r^{2}$ & $r^{2}$ change & $\mathrm{F}$ \\
\hline \multirow{2}{*}{1} & (Constant) & 0.000 & 0.008 & \multirow{2}{*}{0.901} & \multirow{2}{*}{0.813} & \multirow{2}{*}{0.813} & \multirow{2}{*}{1240.8} \\
\hline & Light & 0.901 & 35.216 & & & & \\
\hline \multirow{3}{*}{2} & (Constant) & 0.000 & 0.010 & \multirow{3}{*}{0.928} & \multirow{3}{*}{0.859} & \multirow{3}{*}{0.048} & \multirow{3}{*}{877.6} \\
\hline & Light & 0.527 & 12.024 & & & & \\
\hline & Cover & 0.434 & 9.866 & & & & \\
\hline \multirow{4}{*}{3} & (Constant) & 0.000 & -0.005 & \multirow{4}{*}{0.947} & \multirow{4}{*}{0.896} & \multirow{4}{*}{0.037} & \multirow{4}{*}{825.6} \\
\hline & Light & 0.354 & 8.552 & & & & \\
\hline & Cover & 0.467 & 12.311 & & & & \\
\hline & $\vartheta_{\text {out }}$ & 0.241 & 10.088 & & & & \\
\hline \multirow{5}{*}{4} & (Constant) & 0.000 & -0.004 & \multirow{5}{*}{0.956} & \multirow{5}{*}{0.913} & \multirow{5}{*}{0.017} & \multirow{5}{*}{750.0} \\
\hline & Light & 0.225 & 5.375 & & & & \\
\hline & Cover & 0.457 & 13.119 & & & & \\
\hline & $\vartheta_{\text {out }}$ & 0.184 & 7.937 & & & & \\
\hline & Footfall & 0.220 & 7.390 & & & & \\
\hline \multirow{6}{*}{5} & (Constant) & 0.000 & -0.004 & \multirow{6}{*}{0.958} & \multirow{6}{*}{0.916} & \multirow{6}{*}{0.004} & \multirow{6}{*}{626.4} \\
\hline & Light & 0.147 & 3.161 & & & & \\
\hline & Cover & 0.459 & 13.430 & & & & \\
\hline & $\vartheta_{\text {out }}$ & 0.196 & 8.520 & & & & \\
\hline & Footfall & 0.200 & 6.721 & & & & \\
\hline & HVAC & 0.105 & 3.503 & & & & \\
\hline
\end{tabular}

The analysis which excludes $\vartheta_{\text {in }}$ and $\mathrm{RH}_{\text {in }}$ follows the same general pattern described above. For both, the total consumption and refrigeration consumption, the models with four predictors were selected with a correlation coefficient of 0.975 for the total consumption and 0.956 for the refrigeration consumption.

The residuals of the four models plotted in Figure 3 to Figure 6 were also tested for the assumption stated in 2.1. The first assumption of zero average error is always met by SPSS. The second one of normal error distribution was also met 
to a reasonable degree. The third assumption was met by the models for the total consumption, but for the refrigeration this test showed heteroscedasticity. The forth assumption was tested with scatter plots which showed reasonable conformance. The last assumption was also largely met.

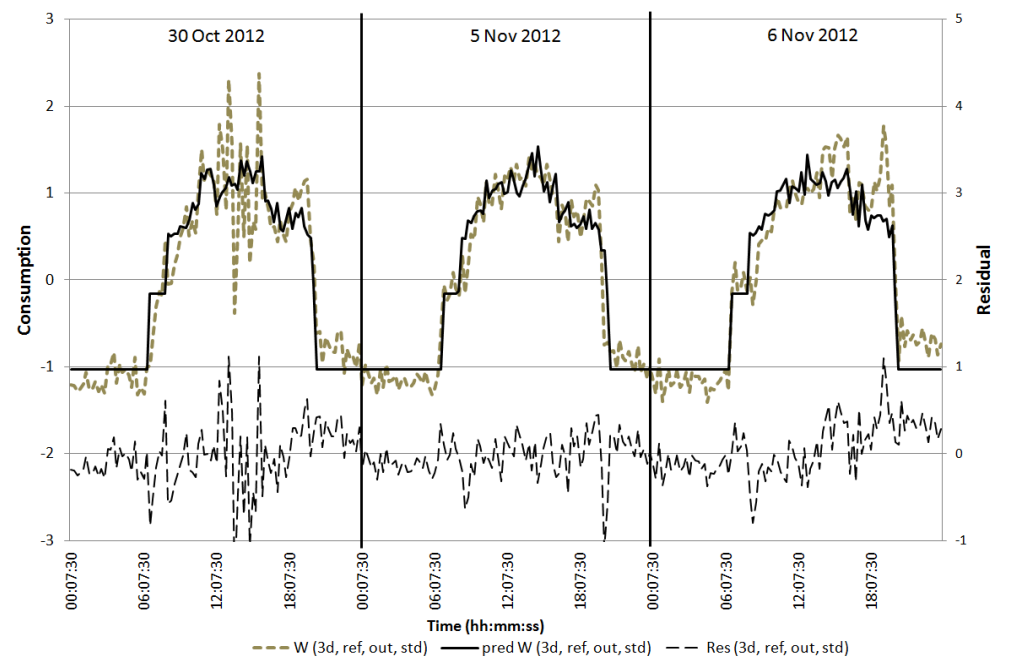

Figure 6: Refrigeration consumption (days 1-3) - predictors: light, cover, $\vartheta_{\text {out }}$ and footfall.

\section{Discussion and conclusions}

This paper presented an explorative study on an UK supermarket to investigate if a limited number of predictors could be used to monitor the energy consumption of the supermarket as a whole and its refrigeration system as the largest consumer. It was found that four-predictor models show a very good fit $(\mathrm{r}>$ 0.95). The two most influential predictors related to large loads, i.e. the store light and the night cover of the refrigerated shelves. Other factors improve the regression model to a lesser degree. The data analysis excluding $\vartheta_{\text {in }}$ and $\mathrm{RH}_{\text {in }}$ used footfall as a new predictor. The close correlation with the inside temperature $(r=0.835)$ suggests that this new predictor substitutes for $\vartheta_{\text {in }}$.

Other studies examining energy consumption and savings in supermarkets from different viewpoints report supportive findings. For instance, Chung et al. [11] suggest a regression model for energy benchmarking which is based on an analysis of 30 supermarkets. In this study the authors normalise their data for degree-days and suggest to include building age, floor area, operation schedule, number of customers and occupants' behaviour, which includes maintenance (the last three predictors are only significant at the $80 \%$ level). This is similar to most of the four-predictor models developed here as they include building timers which are similar to the operation schedule, and, if $\vartheta_{\text {in }}$ and $\mathrm{RH}_{\text {in }}$ are excluded, 
these models also use footfall. Other studies (e.g. Schraps [12] or Tassou et al. [13]) point out that the largest consumers in supermarkets are refrigeration and lighting. These papers also show that HVAC consumes less than $10 \%$ of their examined supermarkets' usage. The models developed above all include lighting and night covers as strong predictors and only two include the operation schedule for the HVAC equipment. This and the fact that the analysis of the data for the refrigeration system also showed up an abnormal situation gives some credence to the approach suggested here.

There seems to be only a very limited amount of academic literature available linking energy monitoring to supermarket energy savings. One of them is by Grayson [14] who examines the "Plan A" implemented by Marks and Spencer. He refers to a "champion for Plan A" who was aware of why the electricity use was unusually high, indicating that actions could be taken if abnormal levels of electricity consumption were detected.

On the other hand, there is some grey literature available, for example the two documents [15] and [16] by the Carbon Trust. The first document [15] lists and briefly discusses 69 different technologies and techniques which can save energy or reduce $\mathrm{CO}_{2}$ emissions in or through supermarkets. These range from LED lights through store dehumidification to staff training. One of these techniques, which can be implemented relatively easily, is cleaning and maintenance. According to [15] poorly maintaining heat exchangers can increase energy use by up to $10 \%$ and critically low refrigeration charge raises electricity consumption by between $11 \%$ and $15 \%$. Under the heading 'Maintenance' in [16], it is suggested to examine data recording procedures to establish if abnormal energy use can be easily detected. Hence, the approach suggested in this study here could be of help in this respect.

Although the approach to monitoring energy use suggested in this paper could be of merit, it should be pointed out that the results presented here refer only to an explorative study and should be extended so that, for instance, a wider range of temperature and humidity is covered. It could also be investigated if an hourly analysis, or other forms of data processing (e.g. data filters), may give more useful results, as the graphs in this paper, although averaged over 15-min intervals, are still quite spiky, which may lead to erroneous conclusions by the ultimate end user. Another approach could be to see if third party data, such as information from utility companies or national weather data, can be used to avoid installing sub-meters.

\section{Acknowledgements}

The authors would like to gratefully acknowledge the help of Emerson Retail Solutions, Suffolk, UK and Marks \& Spencers, UK.

\section{References}

[1] Sullivan, R. and A. Gouldson, Are there limits to energy efficiency for supermarkets?, in The Guardian 2012. 
[2] Rhiemeier, J.-M., et al., Comparative Assessment of the Climate Relevance of Supermarket Refrigeration Systems and Equipment, 2009, Umweltbundesamt: Dessau-Roßlau.

[3] Mohammed, A.H., B. Alias, and W.W. Choong. Energy awareness development process model. in Proceedings of The 4th Micra Conference. 2005. Faculty of the Built Environment, University of Malaya, Kuala Lumpur, Malaysia.

[4] Hansen, M. and M.G. Rasul. Performance assessment and improvement of an existing air conditioning system of a supermarket: A case study on Bi-Lo supermarket. in 3rd IASME/WSEAS International Conference on Energy \& Environment. 2008. University of Cambridge: World Scientific and Engineering Academy and Society (WSEAS).

[5] Jeremić, B., Energy efficiency through improved maintenance. Tribology in Industry, 2000. 27: p. 3-4.

[6] Yik, F.W.H., W.L. Lee, and C.K. Ng, Building energy efficiency and the remuneration of operation and maintenance personnel. Facilities, 2002. 20(13/14): p. 406 - 413.

[7] ASHREA, 1997 ASHRAE Handbook1997, Atlanta: American Society of Heating, Refrigerating and Air-Conditioning Engineers.

[8] Arias, J., Energy Usage in Supermarkets: Modelling and Field Measurements, 2005, Kungliga Tekniska Hogskolan (Sweden): Sweden.

[9] Montfomery, D.C., E.A. Peck, and G.G. Vining, Introduction to Linear Regression Analysis. 4th ed 2006, Hoboken, N.J: Wiley-Interscience.

[10] Anderson, D.R., D.J. Sweeney, and T.A. Willams, Essential of Modern Business Statitics 2004, Mason: South-Western.

[11] Chung, W., Y.V. Hui, and Y.M. Lam, Benchmarking the energy efficiency of commercial buildings. Applied Energy, 2006. 83(1): p. 1-14.

[12] Schraps, S., Energiekostenreduzierung in Supermärkten. Kälte Klima Aktuell, 2005(2): p. 26-30.

[13] Tassou, S.A., et al., Energy consumption and conservation in food retailing. Applied Thermal Engineering, 2011. 31(2-3): p. 147-156.

[14] Grayson, D., Embedding corporate responsibility and sustainability: Marks \& Spencer. Journal of Management Development, 2011. 30 (10): p. 1017 1026.

[15] Carbon Trust. Refrigeration Road Map. 2012 [Accessed: 24/11/2012]; Available from: http://www.carbontrust.com/media/147175/j7924_ctg021_ refrigeration_road_map_aw.pdf.

[16] Carbon Trust. Refrigeration systems. 2011 [Accessed: 21/11/2012]; Available from: www.carbontrust.com/media/13055/ctg046_refrigeration systems.pdf. 